\title{
C-glucosidic ellagitannin concentrations variability during the years in Syrah wines from Languedoc vineyard
}

\author{
Zuriñe Rasines-Perea ${ }^{1,2}$, Rémi Jacquet ${ }^{3}$, Michael Jourdes ${ }^{1,2}$, Stéphane Quideau ${ }^{3}$, and Pierre-Louis Teissedre ${ }^{1,2, a}$ \\ ${ }^{1}$ Univ. Bordeaux, ISVV, EA 4577, Enologie, 210 Chemin de Leysotte, 33140 Villenave d'Ornon, France \\ ${ }^{2}$ INRA, ISVV, USC 1366 CEnologie, 33140 Villenave d'Ornon, France \\ ${ }^{3}$ Institut des Sciences Moléculaires (CNRS-UMR 5255), Institut Européen de Chimie et Biologie, Université de Bordeaux, \\ 2 rue Robert Escarpit, 33607, Pessac, France
}

\begin{abstract}
C$-Glucosidic ellagitannins, which are the main polyphenolic compounds in oak heartwood, are extracted by wine during aging in oak barrels. The $C$-glucosidic ellagitannins were extracted and purified (> 95\% pure) from Quercus robur heartwood and the hemisynthesis of acutissimins A and B, as well as that of epiacutissimins A and B were performed in an acidic organic solution to identified and quantified their concentration ranges by HPLC-UV-MS in 17 Syrah wine samples from the same cultivar area, Languedoc, same quality wood of French oak barrel, same time of oak barrel ageing (12 months) and different ageing period (years from 1999 to 2011). Unlike our first hypothesis, the linear relationship of a reduction in the total content of ellagitannins with the time spent in bottles is not visible.
\end{abstract}

\section{Introduction}

During wine aging in oak barrels, two large families of molecules are extracted; non-tannin compounds (e.g., aldehydes and acids phenols, coumarins, lignin, polysaccharides, volatile compounds, aliphatic compounds) and tannic compounds (hydrolyzable and condensed tannins). Their quantities have strongly influences on the sensory perceptions of wines [1-3].

The $C$-glucosidic ellagitanins belong to the hydrolyzable tannin family. They have a specific structure consisting of an open-chain glucose core acylated in positions $\mathrm{O} 4$ and $\mathrm{O} 6$ by a hexahydroxydiphenoyl unit (HHDP) and in positions $\mathrm{O} 2, \mathrm{O} 3$ and $\mathrm{O} 5$ by a nonahydroxyterphenoyl unit (NHTP) with a $C$-glucosidic linkage to the glucose $\mathrm{C} 1$ position (Fig. 1). Vescalagin (1) and its epimer castalagin (2) are found respectively at average amounts of 9 and $14 \mathrm{mg} / \mathrm{g}$ in dry french oak wood being. The first $C$-glucosidic ellagitanins to be isolated and characterized 30 years ago from Castanea (chestnut) and Quercus (oak) species [4-6]. Six other ellagitannins were isolated thereafter, the glycosylated monomers with lyxose, grandinin ( $3 \mathrm{mg} / \mathrm{g}$ of dry wood), or xylose, roburin E $(3.2 \mathrm{mg} / \mathrm{g}$ of dry wood), two not glycosilated dimers, roburins A and D $(2.5$ and $3.8 \mathrm{mg} / \mathrm{g}$ of dry wood, respectively), and two glycosylated dimers, roburins $\mathrm{B}$ and C (2.8 and $2.3 \mathrm{mg} / \mathrm{g}$ of dry wood, respectively) (3-8) (Fig. 1) [7-9]. Vescalagin (2) and castalagin (1) represent 40 to $60 \%$ of ellagitannins in Quercus petraea and robur [10-12], but these proportions can vary from one species of oak to another [13]. These molecules are highly soluble in hydroalcoholic solutions, which is the raison why they

a e-mail: pierre-louis.teissedre@u-bordeaux.fr are gradually extracted by the wine solution during barrel aging.

These $C$-glucosidic ellagitannins are continuously transformed through condensation, hydrolysis, and oxidation reactions. The formation of flavano-ellagitannins (9-12) and the $\beta-1-O$-ethylvescalagin (13) in red wines aged in oak barrels has been reported [14-18] (Fig. 1). These $C$-glycosidic ellagitannins and flavanoellagitannin hybrids exhibit important biological properties as antioxidant, antitumoral, anti-inflammatory, antibacterial, and antiviral $[14,19,20]$. They can also affect the astringency of the wine, since, as procyanidins, they have the ability to precipitate proteins, in particular the salivary proteins in the oral cavity [21-24].

Several factors can influence the ellagitannins content in oak wood [9], such as the oak species (Quercus robur and Quercus petraea), the geographical origin [25,26], the age [27], the topography $[7,28]$ and the geographic location of the wood piece in the trees $[27,29]$, as well as the processing of wood in cooperage (i.e., type and duration of drying and toasting) [30,31]. Moreover, the age of the barrels is also important [32].

Some studies about red wine aged in oak barrels have been performed [33-35], but no study has examined the behavior of the ellagitannins in wine after the bottleling process. Thus, the aim of this study was to monitor and compare the evolution kinetics of the oak native $C$-glucosidic ellagitannins, their flavano-ellagitannin hybrids and the $\beta-1-O$-ethylvescalagin in wines.

\section{Materials and methods}

\subsection{General}

Chlorogenic acid (>95\%), formic acid (>95\%) and acetic acid were purchased from Sigma-Aldrich 


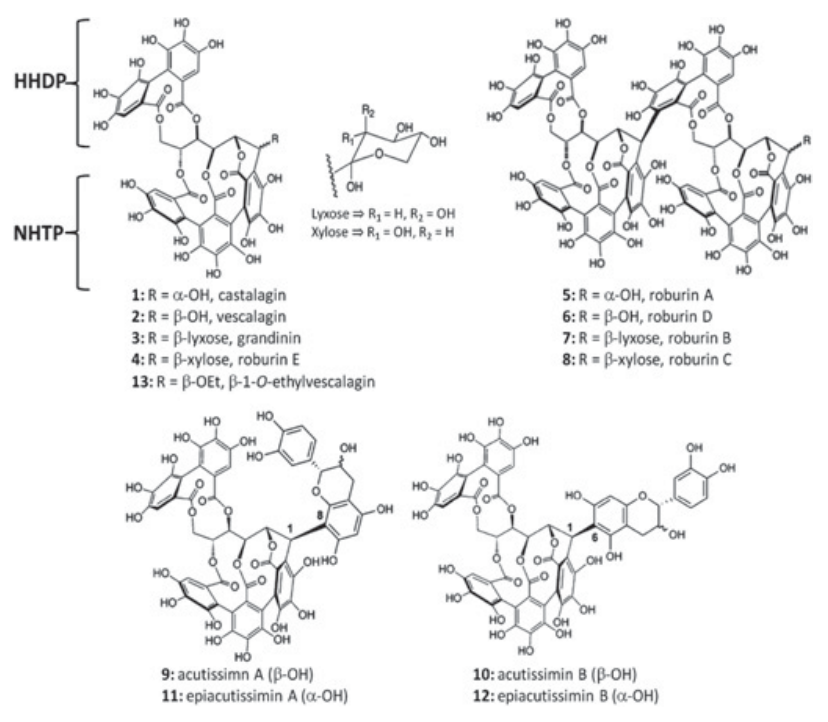

Figure 1. Structures of $C$-glucosidic ellagitannins 1-8 found in heartwood of Quercus species and structures of the vescalagin derivatives 9-13.

(St Quentin Fallavier, France). Methanol (HPLC grade quality, > 99.8\%) and TSK gel HW 50F were purchased from VWR (Strasbourg, France). Acetone was obtained from Xilab (Atlantic labo, Bordeaux, France). Milli-Q (Millipore) water was prepared using a Sarterius-arium 611 system.

Castalagin (1) was extracted from Quercus robur heartwood [18] and the hemisynthesis of the acutissimins A/B $(9 / 10,>95 \%$ pure), the epiacutissimins $A / B$ $(11 / 12,>95 \%$ pure $)$, and the B-1-O-ethylvescalagin $(13,98 \%$ pure) were performed in acidic media $[1.5 \%(\mathrm{v} / \mathrm{v}) \mathrm{TFA} / \mathrm{THF}]$ at $60^{\circ} \mathrm{C}$ as previously described $[15,16]$.

Red wines samples (17 vintages raging from 1991 to 2011) from Domain de l'Aiguelière Languedoc vineyard in Appellation Montpeyroux were analyzed. Each wine made from the same syrah parcel and aged in new French oak barrels for 12 months.

\subsection{Red wine sample preparation}

A fractionation procedure used prior to the HPLC-UVMS analysis of the red wine samples was adapted from the previously described procedure $[18,33]$. Indeed, each red wine sample $(120 \mathrm{~mL})$ was evaporated under vacuum and the resulting viscous dark red residue was dissolved in $\mathrm{H}_{2} \mathrm{O} / \mathrm{HCOOH}(996: 4,20 \mathrm{~mL})$. The obtained solutions were then loaded on a column $(55 \mathrm{~mm} \times 25 \mathrm{~mm})$ that had been packed with TSK HW 50F resin, which had been previously swelled overnight in methanol and equilibrated with $\mathrm{H}_{2} \mathrm{O} / \mathrm{HCOOH}(996: 4,100 \mathrm{~mL})$. After loading $5 \mathrm{~mL}$ of the sample on the column, the acidic aqueous solvent $(50 \mathrm{~mL})$ was first used to wash out tartaric acid and sugars and, in a second step, an acidic hydromethanolic solvent $\left(\mathrm{H}_{2} \mathrm{O} / \mathrm{MeOH} / \mathrm{HCOOH}\right.$ (298:698:4), $\left.100 \mathrm{~mL}\right)$ was used to elute important amounts of the non ellagic polyphenols.

Finally, the ellagitannin fraction was eluted using $\mathrm{H}_{2} \mathrm{O}$ /acetone/HCOOH (298:698:4, $\left.100 \mathrm{~mL}\right)$. This fraction was evaporated under reduced pressure to furnish a reddish light brown residue, which was dissolved in $\mathrm{H}_{2} \mathrm{O} / \mathrm{HCOOH}$
(996:4, $1 \mathrm{~mL}$ ) containing $20 \mathrm{mg} / \mathrm{L}$ of chlorogenic acid used as internal standard and filtered $(0.45 \mu \mathrm{m})$ prior to HPLCUV-MS analysis.

\subsection{HPLC-UV-MS conditions for ellagitannins quantification in wine}

The ellagitannins composition in red wines was determined using a Thermo-Finnigan Surveyor HPLC system containing an autosampler (Surveyor autosampler Plus), a quaternary pump (Surveyor LC pump Plus), and a UV-vis detector (Surveyor PDA Plus) controlled by Xcalibur data treatment system. This HPLC system was also coupled to a Thermo-Finnigan LCQ Advantage spectrometer equipped with an ion trap mass analyzer. The electrospray ionization and mass detection was performed in negative ion mode with the following optimized parameters: capillary temperature, $300{ }^{\circ} \mathrm{C}$; capillary voltage, $-46 \mathrm{~V}$; nebulizer gas flow, $1 \mathrm{~L} / \mathrm{min}$; desolvation gas flow, $0.25 \mathrm{~L} / \mathrm{min}$; and spray voltage, $5 \mathrm{kV}$. These analyses were carried out in technical duplicates on a $250 \times 4.6 \mathrm{~mm}, 5 \mu \mathrm{m}$, Lichrospher 100 RP 18 column. The used mobile phases were solvent A $\left[\mathrm{H}_{2} \mathrm{O} / \mathrm{HCOOH}\right.$ (996:4)] and solvent B [MeOH/HCOOH (996:4)] and the elution gradient was 0$3 \%$ of $\mathrm{B}$ in $5 \mathrm{~min}, 3$ to $20 \%$ of $\mathrm{B}$ in $20 \mathrm{~min}$, and 20 to $100 \%$ of $B$ in 50 min with a flow rate set at $1 \mathrm{~mL} / \mathrm{min}$ and a detection wavelength set at $280 \mathrm{~nm}$. The $C$-glucoside ellagitannins (1-8), flavano-ellagitannins (9-12), and B-1-O-ethylvescalagin (13) were separately identified and assigned by comparison of their UV spectra and mass spectra with purified or hemisynthesized standards. The quantification of each compound was performed using their molecular ion (Table 1). The concentrations of $C$ glucosidic ellagitannins (1-8) and $B-1-O$-ethylvescalagin (13) were expressed as equivalents of castalagin (2), whereas flavano-ellagitannins (9-12) concentrations were expressed as equivalents of acutissimin A (9).

\subsection{Sensorial analyze}

The sensorial analyze took place in a standard room adapted to the V 09-105 norm. This room was equipped with individual testing booth (10 in numbers) to separate each individual judge and the temperature is set at $20^{\circ} \mathrm{C}$. The testings are carried to distant meal times $(10 \mathrm{~h}-12 \mathrm{~h}$ or $15 \mathrm{~h}-18 \mathrm{~h}$ ) to eliminate sensory disturbances.

This sensory analysis was held to find a connection between the total content of 1-13 with the bitterness and astringency intensities found by the judges which was composed of 20 trained experts.

The intensities of the descriptors were rated on a $10 \mathrm{~cm}$ linear graphic scale [36]; the intensity level of each descriptor was then expressed as the mean value of all the judges. The samples were presented in randomly coded, clear, $125 \mathrm{~mL}$ glasses; distilled water was provided for rinsing between wines.

\section{Results}

\subsection{C-glucosidic ellagitannins analyses}

The concentration of the ellagitannins 1-8 and $\mathbf{1 3}$ as well as the flavano-ellagitannins 9-12 was determined in the 17 red wine vintages corresponding to Languedoc vineyard. These analyses were carried out with wines from the same 
Table 1. HPLC retention times and mass fragmentation patterns of the reference compounds 1-13 and the internal standard.

\begin{tabular}{|c|c|c|}
\hline Compounds & $\begin{array}{l}\text { Retention } \\
\text { time (min) }\end{array}$ & $\mathbf{m} / \mathbf{z}$ \\
\hline Castalagin (1) & 22.80 & $\begin{array}{l}933^{\mathrm{a}}, 915,613, \\
301\end{array}$ \\
\hline Vescalagin (2) & 13.03 & $\begin{array}{l}933^{\mathrm{a}}, 915,613, \\
301\end{array}$ \\
\hline Grandinin (3) & 8.21 & $\begin{array}{l}1,065^{\mathrm{a}}, 915,613, \\
301\end{array}$ \\
\hline Roburin A (5) & 7.42 & $\begin{array}{l}1,849,933,924^{\mathrm{a}}, \\
915,301\end{array}$ \\
\hline Roburin B (7) & 7.92 & $\begin{array}{l}1,981,1,065,990^{\mathrm{a}} \text {, } \\
915,301\end{array}$ \\
\hline Roburin C (8) & 7.96 & $\begin{array}{l}1,981,1,065,990^{\mathrm{a}}, \\
915,301\end{array}$ \\
\hline Roburin D (6) & 10.55 & $\begin{array}{l}1,849,933,924^{\mathrm{a}}, \\
915,301\end{array}$ \\
\hline Roburin E (4) & 15.16 & $\begin{array}{l}1,065^{\mathrm{a}}, 915,613, \\
301\end{array}$ \\
\hline Acutissimin A (9) & 50.62 & $\begin{array}{l}1,205^{\mathrm{a}}, 915,613, \\
602,301\end{array}$ \\
\hline Acutissimin B (10) & 62.02 & $\begin{array}{l}1,205^{\mathrm{a}}, 915,613, \\
602,301\end{array}$ \\
\hline Epiacutissimin A (11) & 67.49 & $\begin{array}{l}1,205^{\mathrm{a}}, 1,053,915 \\
613,602,301\end{array}$ \\
\hline Epiacutissimin B (12) & 44.92 & $\begin{array}{l}1,205^{\mathrm{a}}, 1,053,915, \\
613,602,301\end{array}$ \\
\hline B-1-O-ethylvescalagin (13) & 42.32 & $\begin{array}{l}961^{\mathrm{a}}, 915,480, \\
301\end{array}$ \\
\hline Chlorogenic acid & 56.63 & $353^{\mathrm{a}}$ \\
\hline
\end{tabular}

vinery which eliminates a few variables that can influence their concentration since all the studied vintage were obtained from the grape variety grown on the same parcel and aged the same time in French oak barrel obtained from the same cooperage company.

The graphic in Fig. 2 corresponds to the total contents of ellagitannins 1-8 and 13, as well as flavanoellagitannins 9-12 obtained for each vintage analysis from the oldest wine (1991) to the youngest (2011).

First, it should be noted that the concentrations of roburin A (5), acutissimin A (9) and epiacutissimin A (11) are not represented on the graphic since they were not detected in the analyzed samples. Unlike our first hypothesis, the linear decreasing of the total ellagitannins content with time spent in bottles is was not observed. Moreover, an increasing of the flavano-ellagitannins 9-12 concentration due to the reaction between vescalagin (2) and catechin or epicatechin were also not highlighted. Indeed, the content of vescalagin (2) in the red wine from 1999 vintage is the double $(0.214 \mathrm{mg} / \mathrm{L})$ of castalagin (1) content $(0.105 \mathrm{mg} / \mathrm{L})$. Such data is unusual since generally, in oak wood the concentration of castalagin (1) is higher than the vescalagin (2) values. Furthermore, the concentrations obtained for the $\beta$-1- $O$-ethyl-vescalagin (13) or roburin E (4) appeared to be remarkably high. Indeed, they are greater than the contents of castalagin in 1991, 1994, 1997, 1998 2002, 2006, 2007 and 2011 vintages. This data may indicates a higher stability of $\beta$-1- $O$-ethyl-vescalagin (13) during red wine aging in bottles.

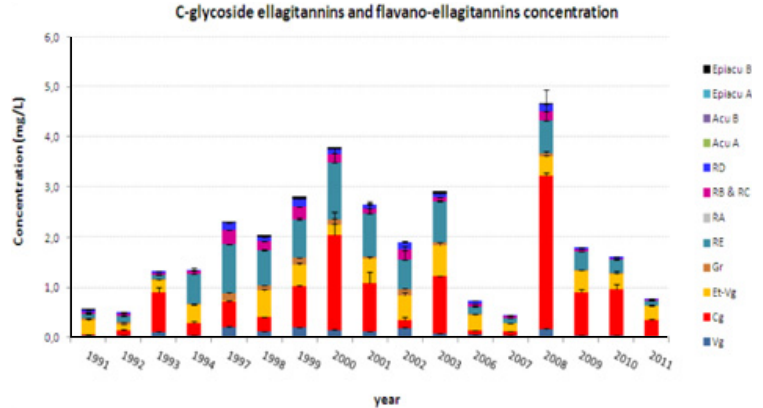

Figure 2. $C$-glucosidic ellagitannins and flavano-ellagitannins concentrations achieved for the 17 wines analyzed from the same Languedoc vineyard.

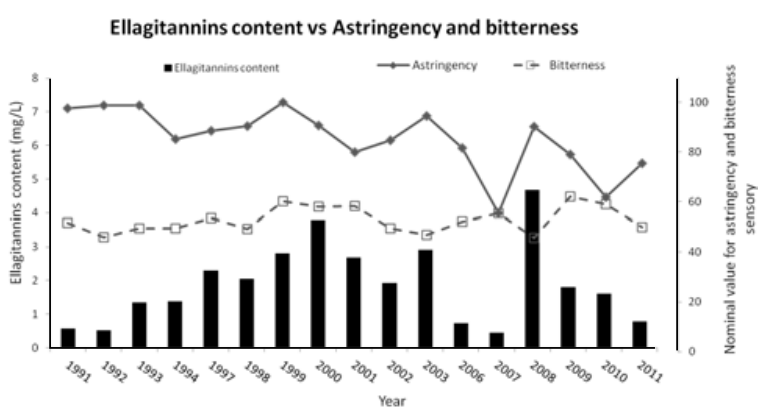

Figure 3. A graphic comparison between the results obtained for the total ellagitannins content versus astringency and bitterness panel perception.

\subsection{Sensorial test}

Regarding the sensory tests, the answers given by the judges showed that there was slight increasing tendency for astringency according to the time spend in bottle for the wine (Fig. 2). In this way, the oldest analyzed wine had a higher astringency perceived by the panel than the youngest wine. Moreover, the bitterness perception appeared to be stable over time independently of the total ellagitannin content.

\section{Conclusions}

This investigation screened the evolution of the $C$-glucoside ellagitannins and flavano-ellagitannins contents during bottle ageing in order to try to find a relationship between their concentration and the time spend by the wine in bottle. Moreover, investigation was also performed in order to find a link between these ellagitannins concentration and the sensory perception of the red wine. Although the concentrations of ellagitannins and flavano-ellagitannins unwire not related with the time spend by the wine in bottel, there was a low increase in astringency perception. Indeed the youngest wine exhibited lower astringency intensity than the most aged wine, whereas bitterness remains stable.

The lack of correlation between ellagitannin content, sensory properties, and time spend in bottles might be due to the formation of oxidative derivative which were not quantified in our study. It is known that the flavano-ellagitannins compounds can be transformed by an oxidative reaction resulting in the mongolicains-like [37] molecules that were not quantified during this study. These evolution compounds may have an important content in 
red wine as well as an impact on its sensory perception. Moreover, the heterogeneity of wood is an important variable that can gives unlikeable responses, as there are a lot of factors that are going to be implicit in the oak wood election [7, 9, 25-29].

Further investigation must be performed in order to estimate the overall impact of these $C$-glucoside ellagitannins and vescalagin derivatives on red wine organoleptic perceptions.

We thanks Domaine l'Aigueliere, Montpeyroux, France for providing the wine samples for analyses and tasting.

\section{References}

[1] B. Monties, Connaissance Vigne Vin, 21, 169-190 (1987)

[2] J. L. Puech, J Int Sci Vigne Vin, 81, 123-134 (1992)

[3] J. Michel, M. Jourdes, M.A. Silva, T. Giordanengo, N. Mourey, P.-L. Teissedre, J Agr Food Chem, 59, 5677-5683 (2011)

[4] W. Mayer, W. Gabler, A. Riester, H. Korger, Liebigs Ann Chem, 707, 177-181 (1967)

[5] W. Mayer, H. Seitz, J. C. Jochims, K. Schauerte, G. Schilling, Liebigs Ann Chem, 751, 60-68, (1971)

[6] W. Mayer, H. Seitz, J. C. Jochims, Liebigs Ann Chem, 721, 186-193 (1969)

[7] A. Prida; J. C. Boulet, A. Ducousso, G. Nepveu, J. L. Puech, Ann For Sci, 63, 415-424 (2006)

[8] C. L. M. Herve du Penhoat, Michon, V. M. F. A. Ohassan, S. Peng, A. Scalbert, D. Gage, Phytochem,30, 329-332 (1991)

[9] C. L. M. Herve du Penhoat, V. M. F. Michon, S. Peng, C. Viriot, A. Scalbert, D. Gage, J Chem Soc Perkin Trans, 1, 1653-1660 (1991)

[10] B. Fernández de Simón, E. Cadahía, E. Conde, M. C. García-Vallejo, Holzforschung, 53, 147-150 (1999)

[11] G. Masson, M. Moutounet, J. L. Puech, Am J Enol Vitic, 46, 262-268 (1995)

[12] G. Masson, J.-L. Puech, M. Moutounet, Phytochem, 37,1245-1249 (1994)

[13] N. Vivas, Manuel de Tonnellerie à l'usage des utilisateurs de futaille (Féret, Ed. Bordeaux, 2002)

[14] S. Quideau, M. Jourdes, D. Lefeuvre, P. Pardon, C. Saucier, P-L. Teissedre, Y. Glories, Ellagitannins An Underestimated Class of Plant Polyphenols: Chemical Reactivity of $C$-Glucosidic Ellagitannins in Relation to Wine Chemistry and Biological Activity. In Recent Advances in Polyphenol Research. Santos-Buelga, C., Escribano-Bailon, M. T., Lattanzio, V., Eds; Wiley-Blackwell Publishing: Oxford, Vol. 2, Chapter 4, 81-137 (2010)

[15] S. Quideau, M. Jourdes, C. Saucier, Y. Glories, P. Pardon, C. Baudry, Angew Chem Int Ed, 42, 6012-6014 (2003)
[16] S. Quideau, M. Jourdes, D. Lefeuvre, D. Montaudon, C. Saucier, Y. Glories, P. Pardon, P. Pourquier, ChemEur J, 11, 6503-6513 (2005)

[17] M. Jourdes, D. Lefeuvre, S. Quideau, $C$-Glycosidic Ellagitannins and Their Influence on Wine Chemistry. In Chemistry and Biology of Ellagitannins - An Underestimated Class of Bioactive Plant Polyphenols. Quideau, S., Ed; World Scientific Publishing: Singapore, Chapter 9, 320-365 (2009)

[18] C. Saucier, M. Jourdes, Y. Glories, S. Quideau, J Agr Food Chem, 54, 7349-7354 (2006)

[19] S. Quideau, T. Varadinova, D. Karagiozova M. Jourdes, P. Pardon, C. Baudry, P. Genova, T. Diakov, R. Petrova, Chem Biodiv, 1, 247-258 (2004)

[20] N. Vilhelmova-Ilieva, R. Jacquet, S. Quideau, A. S. Galabov, Antiviral Res. 110, 104-114 (2014)

[21] N. Vivas, Y. Glories, Am J Enol Vitic, 47, 103-107 (1996)

[22] A. Glabasnia, T. Hofmann, J Agr Food Chem, 54, 3380-3390 (2006)

[23] C. Santos-Buelga, A. Scalbert, J Sci Food Agr, 80, 1094-1117 (2000)

[24] M. K. Quinn, V. L. Singleton, Am J Enol Vitic, 36, 148-155 (1985)

[25] J. R. Mosedale, J. L. Puech, F. Feuillat, Am J Enol Vitic, 50, 503-511 (1999)

[26] J. Marco, J. Artajona, M. S. Larrechi, F.X. Rius, Am J Enol Vitic, 45, 192-200 (1994)

[27] G. Masson, M. Moutounet, J. L. Puech, Am J Enol Vitic, 46, 262-268 (1995)

[28] L. Bergès, R. Chevalier, Y. Dumas, A. Franc, J.-M. Gilbert, Ann For Sci, 62, 391-402 (2005)

[29] G. Masson, J. L. Puech, M. Moutounet, Bull OIV, 69, 634-657 (1996)

[30] M. D. Hale, K. McCafferty, E. Larmie, J. Newton, J.S. Swan, Am J Enol Vit, 50, 495-502 (1999)

[31] L. Matricardi, A. L. Waterhouse, Am J Enol Vit, 50, 519-526 (1999)

[32] C. Viriot, A. Scalbert, C. Lapierre, M. Moutounet, J Agr Food Chem, 41, 1872-1879 (1993)

[33] M. Del Alamo-Sanza, I. Nevares-Domínguez, Anal Chim Acta, 563, 255-263 (2006)

[34] M. Jourdes, J. Michel, C. Saucier, S. Quideau, P-L. Teissedre, Anal Bioanal Chem, 401, 1531-1539 (2011)

[35] I. García-Estévez, M. T. Escribano-Bailón, J. C. Rivas Gonzalo, C. Alcalde-Eon, J Agr Food Chem, 60, 1373-1379 (2012)

[36] E. Chambers, M. Baker Wolf,Sensory testing methods, $2^{\text {nd }}$ edition, ASTM, West Conshohocken (1996)

[37] E. Petit, D. Lefeuvre, R. Jacquet, L. Pouységu, D. Deffieux, S. Quideau, Angew Chem Int Edit, 52, 11530-11533 (2013) 